\title{
A Question of Leverage
}

\author{
Quan-Hoang Vuong \\ World Bank / IFC \\ Vietnam Investment Review
}

March 24, 1997 


\section{A question of leverage}

Vuong Quan Hoang examines the problems of debt and capital faced by small and medium sized enterprises (SMEs)

THE question of how a SMEs, most of their capital firm's value moves in response to changes in its debt-equity ratio is well known to all financial managers. It remained unanswered until papers by Durance (1952), Modigliani and M.Miller (1958), and Myers (1977), addressed the issue systematically under a set of assumptions.

Of the capital structure literature, the famous Modigliani-Miller hypothesis (MM) has contributed a great deal to the conceptual development of finance professionals. Following MM, financial distress costs have added to the build-up of a bigger picture through which corporate finance issues can be better understood.

The MM approach deals with a firm's value once decides to leverage its capital structure. Given the existence of corporate income tax. the hypothesis pointed out that firm may gain in its value thanks to a debt tax shield. The shield indicates firm could benefit from a decisio to leverage in two ways: Increased value of operations; and debt capital to finance operations.

However, the financial distress hypothesis prove that the tax benefit, which firms obtain from financia leverage, would not always be linearly related to debtequity ratios. As there is no method to determine a firm's value in relation to debt proportion, the job of definin optimal capital structure has been left to corporate financial professionals.

Capital shortage of SMEs

SMEs in Vietnam have grown both in number an scale in recent years. However, entrepreneurs face many constraints, of which financial resources have been the most difficult. Being asked about future schemes, all of the 12 SMEs surveyed unveiled their plans to expand by either investing intensively in current or related business, or diversifying their scope of activities.

Because Vietnam lacks securities market, the problems of financing should be addressed in terms of internal equity and external debt.

Taking a look at the investment decisions of value takes the form of property or land. They seem to be betting that rental and related costs will be huge in the future and if they do not invest in premises and land now, high rents might drive them out of business in the future.

This type of investment strategy often eats up 30-60 per cent of a business's capital, leaving less for equipment and working capital financing. Obviously, expansion schemes face the same capital shortage.

But the survey indicates that SMEs pay much attention to investment in equipment and working capital. Planned investment usually ranges from $\$ 400,000$ to $\$ 1.5$ million over a duration of 5 . 10 years. However, the SME owners surveyed also unveiled a puzzle in their financino decisinn

On one hand, SMEs do not have the same access to large domestic banks which is afforded to State-owned enterprises (SOEs). On the other hand, they tend to be skeptical about borrowing, citing such reasons as the comparative safety of internal equity financing. So far, most SMEs have borrowings which serve as short-term working capital.

The debt-equity ratio of the SMEs has stayed very low and long-term debt ratio is almost zero. This partly bears out their skepticism over debt financing. But by overlooking debt financing, SMEs neglect one of the most significant resources that could help fund business expansion.

Whatever comments one may have on the figures, the fact is that firms' skepticism to the alternative of debt financing contributes to their financial constraints. A total reliance on earnings retention should allow SMEs to grow.

But although most of the SMEs surveyed revealed retention levels of $90-100$ per cent, the capital shortage still remained unsolved.

However, findings also show that the only surveyed SME that has been heavily leveraged ( 80 per cent debtequity) is in dire financial straits. This suggests that borrowed funds have not been efficiently managed.

\begin{tabular}{|c|c|c|c|c|c|c|c|}
\hline \multirow[b]{2}{*}{ Business } & \multicolumn{5}{|c|}{ Summary of surveyed SMEs debt issue* } & \multirow[b]{2}{*}{ Paints } & \multirow[b]{2}{*}{ Seafood } \\
\hline & Audio & Plastics & Jewellery & Fans & Wood & & \\
\hline Growth rate & $20 \%$ & $20 \%$ & $20-30 \%$ & $20 \%$ & $0 \%$ & $10 \%$ & $15 \%$ \\
\hline Assets & $\$ 1.1 \mathrm{~m}$ & $\$ 2.0 \mathrm{~m}$ & $\$ 4.0 \mathrm{~m}$ & $\$ 1.2 \mathrm{~m}$ & $\$ 5.0 \mathrm{~m}$ & $\$ 0.5 \mathrm{~m}$ & $\$ 0.8 \mathrm{~m}$ \\
\hline L-T liabilities & $\$ 0$ & $\$ 0$ & \$o & $\$ 0$ & $\$ 0$ & $\$ 0$ & $\$ 0$ \\
\hline S-T liabilities & $\$ 0.05 \mathrm{~m}$ & $\$ 0.6 \mathrm{~m}$ & \$o & $\$ 0$ & $\$ 4.0 \mathrm{~m}$ & $\$ 0$ & $\$ 0.4 m$ \\
\hline L-T debt ratio & $0 \%$ & $0 \%$ & $0 \%$ & $0 \%$ & $0 \%$ & $0 \%$ & $0 \%$ \\
\hline Debt-equity ratio & $4.55 \%$ & $30 \%$ & $0 \%$ & $0 \%$ & $80 \%$ & $0 \%$ & $50 \%$ \\
\hline Capital needs & $\$ 0.4 \mathrm{~m}$ & $\$ 1.0 \mathrm{~m}$ & $\$ 1.5 \mathrm{~m}$ & $\$ 1.2 \mathrm{~m}$ & $\$ 4.0 \mathrm{~m}$ & $\$ 0.4 \mathrm{~m}$ & $\$ 0.8 \mathrm{~m}$ \\
\hline & & & & & & & \\
\hline
\end{tabular}

\section{WE ARE OPEN!}

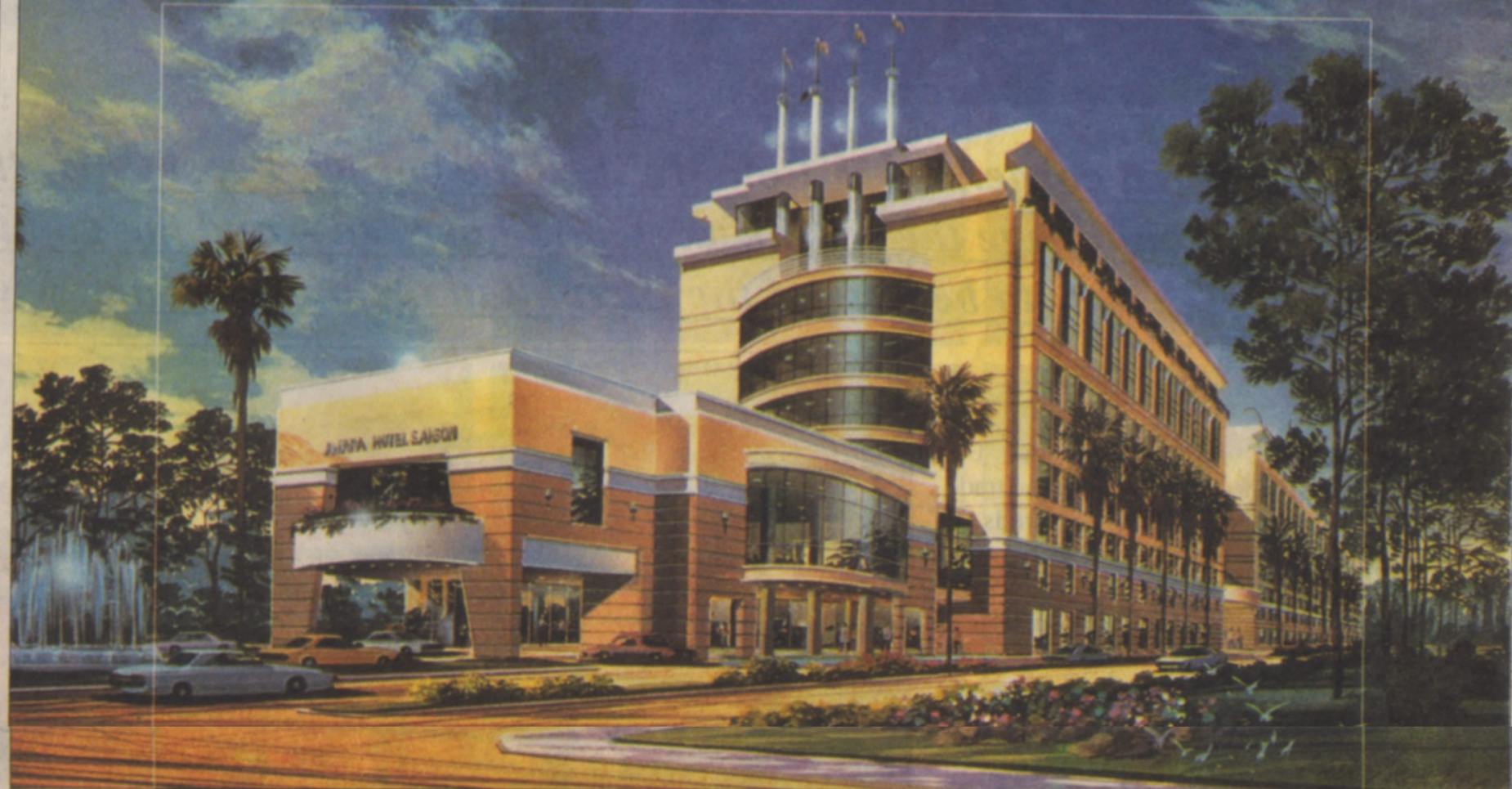

\section{Amara Saigon Warmly Welcomes You With A Complimentary Stay}

Stay with us and experience our generous hospitality. For a 3-night package at US\$98.00++* per night, the third night is with our compliments.

- Airport arrival and departure transfers $\bullet$ Welcome drink • Upgrade to a Deluxe Room

- Welcome fruit basket - Complimentary daily international buffet breakfast

- $20 \%$ discount at all FEB outlets and laundry $\&$ dry-cleaning services • Souvenir gift

(Published rate for Deluxe Room is US\$200)

- Valid till 31 March 1997

Once its doors open to the world, the nine-storey Amara Saigon will be the landmark establishment in urban Ho Chi Minh City.

It will reflect the splendour and charm of Vietnam's rich heritage... and will imbibe the gracious hospitality and efficiency Singapore is famed for.

For the business traveller who wants to be in the heart of things, yet longs for the comfort of home, there is only the Amara Saigon.

\section{AMARA}

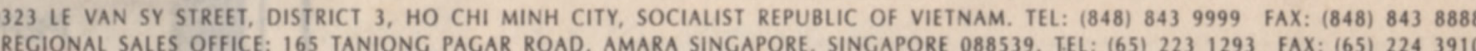

